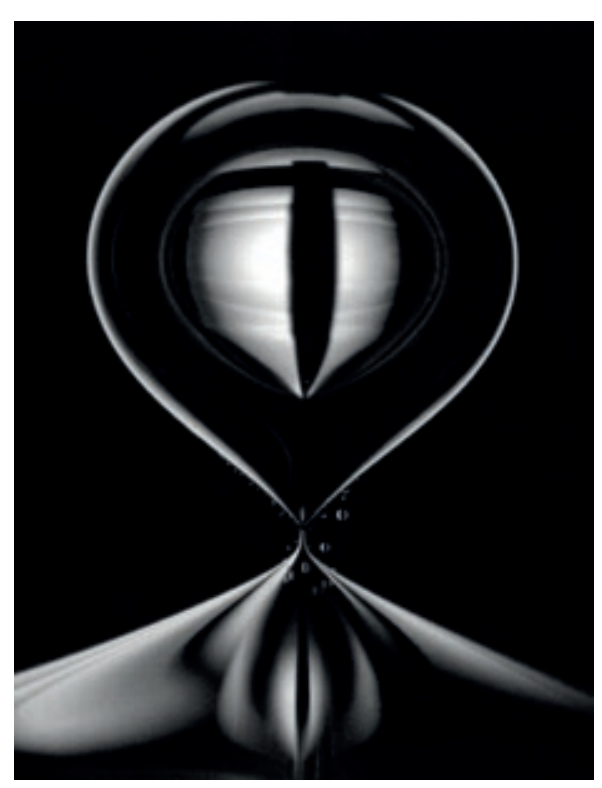

1. Dans l'intimité d'une frontière franchie, par Antoine Lagarde (25 ans, doctorant en mécanique des fluides à l'Institut Jean Le Rond d'Alembert, Paris).

Bulle d'air qui traverse une interface entre de l'eau et de l'huile.

\section{Le concours Beautiful Science de la SFP}

En mars 2019, la Société Française de Physique a lancé Beautiful

Science, un concours d'images et de sons ouvert à tous et portant sur toutes les sciences. Une sélection des œuvres reçues a été présentée au Congrès général 2019 de la SFP et, depuis, elle fait l'objet d'une exposition itinérante.

Parce que science rime aussi avec beauté, créativité et émerveillement, la SFP a désiré inviter tout un chacun à redécouvrir le monde magnifique et mystérieux qui nous entoure à travers le concours Beautiful Science, lancé dans le cadre du Congrès général 2019.

Le thème : Montrer la science dans ce qu'elle a de plus beau et de plus élégant, de l'infiniment petit à l'infiniment grand !

Ce concours d'images et de sons était soutenu par trente-trois organisations partenaires, et parrainé par le collectif français Obvious, fondé par trois amis d'enfance, amateurs d'art et de machine learning, à l'origine de la première peinture d'intelligence artificielle intitulée Edmond de Belamy.

Plus de 360 propositions furent reçues au total : photos, peintures, schémas, dessins, vidéos et pistes audio. Les auteurs, âgés de 9 à 87 ans, présentaient une grande diversité de profils : des contributeurs scientifiques (travaillant dans les différents domaines de la physique, ainsi qu'en informatique, océanographie, paléontologie, agronomie, biologie ou médecine), mais aussi des artistes, une concierge ou encore un agent de sécurité ! Bref, pari réussi pour ce concours qui avait pour objectif de rassembler professionnels comme amateurs de science autour d'un thème fédérateur et enthousiasmant.

Le jury, composé des partenaires de l'opération (voir la bannière en bas de page), a sélectionné quatre œuvres lauréates (figures 1 à 4) et présélectionné dix autres œuvres soumises au vote du public (l'œuvre élue par le public est présentée en figure 5).

\section{L'exposition Beautiful Science}

Une sélection d'une cinquantaine d'œuvres a été exposée au Congrès général de la SFP, qui s'est tenu à la Cité des congrès de Nantes du 8 au 12 juillet 2019. L'exposition, conçue par Julie Villegas et Mayline Gautié, a ensuite voyagé à Saint-Brieuc, où elle fut proposée au public du 5 octobre au 19 novembre dans le cadre du Festival Baie des Sciences, puis du Festival Photo Reporter.

\section{BEAUTIFULSGIENCE}

Vous souhaitez faire venir l'exposition

dans vos locaux?

Rendez-vous sur le site de la SFP

www.sfpnet.fr/ 


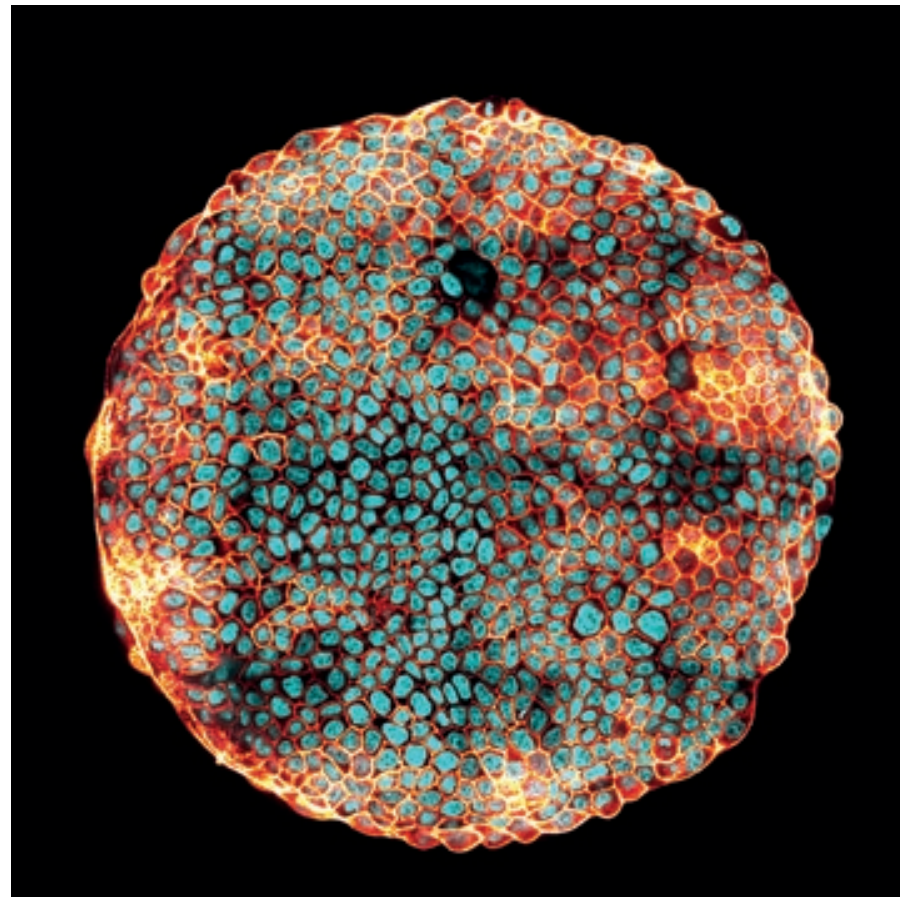

2. Ilot de cellules,

par Nicolas Harmand (26 ans, doctorant en biophysique), David Pereira (31 ans, postdoctorant en biophysique) et Sylvie Hénon (52 ans, professeure des universités à Paris), tous les trois du laboratoire MSC à l'université Paris Diderot.

Des cellules épithéliales ont été mises en culture sur un gel de polyacrylamide où l'on a disposé des disques de protéines d'adhérence à certains endroits. Sur l'image, prise par microscopie confocale à fluorescence, les noyaux des cellules sont de couleur cyan, et leurs contours dans une nuance de jaune-rouge.

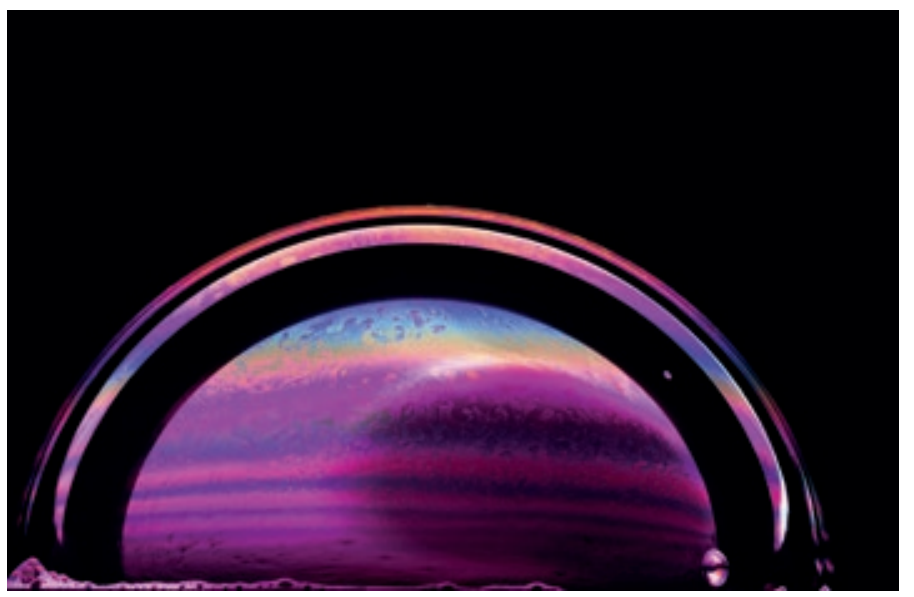

\section{Planète sous cloche,}

par Hubert Klein (47 ans, maitre de conférences au département de physique et chimie de l'université d'Aix-Marseille).

Photographie en champ sombre, au flash, d'une bulle de savon éclairée par le dessous. Une gélatine magenta colore la lumière du flash. On observe des turbulences sur le haut de la bulle, et une variation d'épaisseur du film d'eau savonnée, qui ne sont pas sans rappeler les planètes gazeuses de notre système solaire.

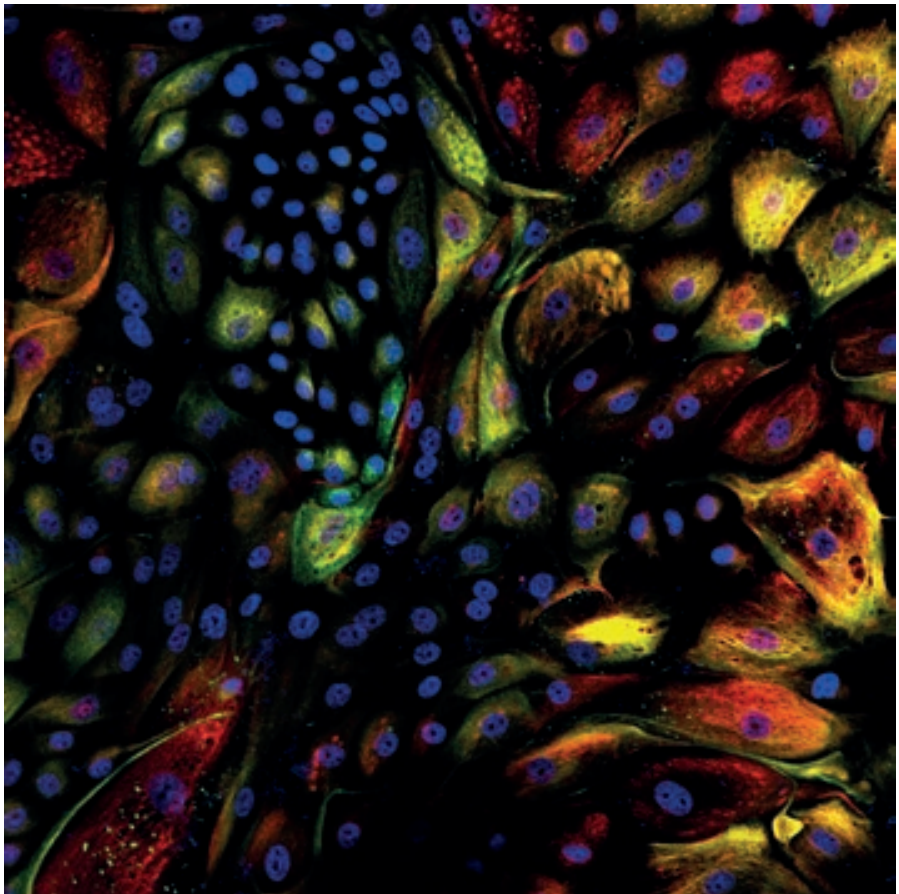

3. Hallucination cellulaire,

par Martine Batailler (62 ans, assistante ingénieure en neuroendocrinologie à I'INRA Val de Loire).

Cellules en culture. En vert et en rouge : marquage de deux protéines du cytosquelette. En bleu : visualisation des noyaux des cellules par coloration de I'ADN.

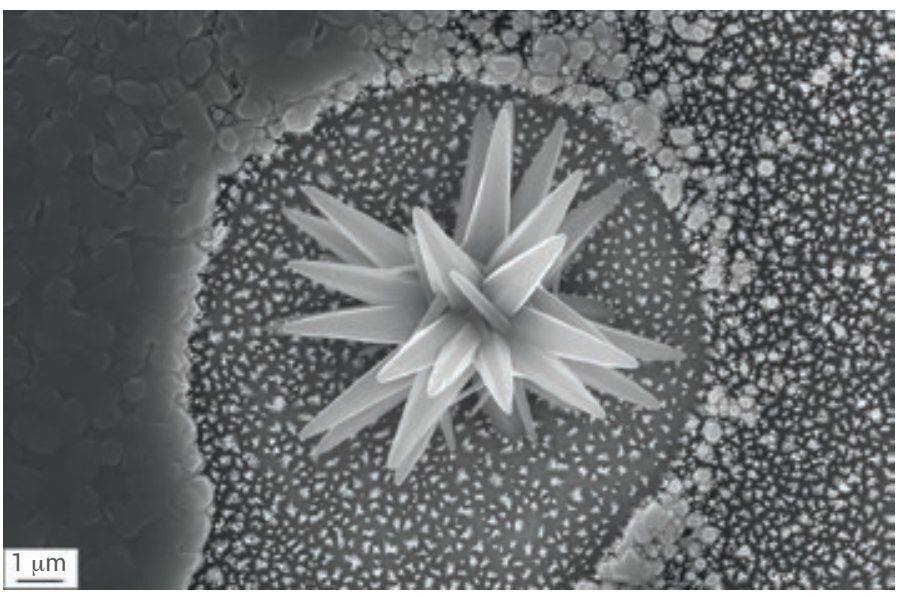

5. Nano-needles in a tiny haystack,

par Pierre Gaffuri (26 ans, doctorant au Laboratoire des matériaux et du génie physique de l'INP à Grenoble).

Les nanofils d'oxyde de zinc ( $\mathrm{ZnO})$ sont des structures prometteuses pour de nombreux dispositifs nanométriques. Leur synthèse par voie chimique peut réserver quelques surprises lorsqu'on les caractérise par microscopie électronique à balayage : on tombe parfois sur des inhomogénéités, amas, trous ou coalescences nanométriques, qui font penser à des nanofils dans une petite botte de foin et qui laissent rêveur. 